\title{
On Approaches Embodying the Market Value of Film and Animation Publication
}

\author{
Yan Yonghao \\ School of Design and Art, Jingdezhen Ceramic Institute \\ Jingdezhen, 333403, China \\ E-mail: $119842011 @ q q . c o m$
}

\begin{abstract}
At present, in the background of that the country vigorously develop the cultural industry, the film and animation publication industry has rapidly developed in our country, and the quantity and quality of products have significantly improved in our country. But its market value has not been fully embodied. Aiming at the current situation of the film and animation publication in our country, the article propose the approaches to promote the market value of film and animation publication according to the characteristic of film and animation publication in our country.
\end{abstract}

Keywords-Film and Animation Publication; Market Value; Cultural Industry

\section{INTRODUCTION}

In recent years, the film and animation publication industry has rapidly developed because of the policy of vigorously developing the film and animation industry in our country. Our country has become the biggest country of the film and animation publication in the quantity of the film and animation works in the world. In addition, the quality of the film and animation works has been obviously improved. But there are still many problems and hidden troubles in the film and animation publication industry in our country, especially, its approaches of embodying the market value have not been effectively expanded. A deep analysis to the film and animation publication industry must be made to better promote the embodiment of the market value of the film and animation publication industry in our country.

\section{MARKET VALUE EMBODIMENT OF THE FILM AND ANIMATION PUBLICATION}

Essentially, commodity is the ultimate attribute of the film and animation. The film and animation publication industry is a cultural industry. The value of the film and animation publication must be embodied in the market. At present, countries around the world are vigorously developing their cultural industries. The film and animation publication industry is seen as an important part of the influence promotion of national culture and strongly supported in Japan, Korea, America and Europe. In our country, the relevant industry support policies have also been introduced which promote the development of the film and animation publication industry and make better embodiment for its market value.

\section{A. The Initial Forming of the Film and Animation Publication Market in Our Country}

The beginning of this century is the initial stage of the development of the film and animation publication in our country. The total box office of the film and animation publication was just 3 million Yuan in our country in 2001, and the film and animation publication market was slow to develop. After 2004, the film and animation publication industry began to rapidly develop again, the market size began to have good momentum, and the box office of the film and animation began to increase. The year 2009 was a favorable development stage of the film and animation publication industry with the promotion of quality and quantity in our country, in which not only the quantity of the film and animation works greatly increased but also the quality of the film and animation works was greatly improved. Many good film and animation works published were accepted by the audience, and the original film and animation works with low quality were eliminated by the audience. Therefore, the film and animation publication industry entered to a stage of stable development in our country.

Pleasant Goat and Big Big Wolf cartoons published in 2009 was accepted by the audience. Especially, the cartoon The Super Adventure took more than 100 million Yuan at the box office, and the related derivatives also made good sales performance. The subsequent three cartoons Desert Trek: The Adventure of the Lost Totem (published in 2010), Moon Castle: The Space Adventure (published in 2011) and ssion incredible: Adventures On The Dragon's Trail (published in 2012) got a good reception in the market, which respectively took 127 million Yuan, 142 million yuan and 166 million Yuan at the box office, and promoted the rapid development of the film and animation publication industry in our country.

\section{B. The Market Value of The Film And Animation \\ Publication Industry Is Not Fully Embodied In Our Country}

During the developing process of the film and animation publication in our country, it requires high technical requirements, long manufacture cycle and high investment costs to promote the quality of the film and animation publication works. In addition, there is a greater uncertainty in the market and the consideration of the development and sales of the works' derivatives must be made after that the film and animation publication works are published. This requires the film and animation publication industry to have 
a relatively long market cultivation cycle in our country in which long term marketing, a mature operation and creative team and higher capital investment must be required for better market efficiency. In order to finish the production of the first 3D animation Thru The Moebius Strip, NBCU invested large number of money on 106 scenes, 1602 shots, 461 scene models, 176 role models and 242 prop models. The total cost of 130 million Yuan was invested on these various and complicated $3 \mathrm{D}$ production technology. But this animation did not gain the sensational effect after its release. It had only 100,000 Yuan at the box office in Shanghai, only less than 30,000 Yuan in Guangzhou, and even only 10,000 Yuan in Nanjing. It is the main reason of the film's failure that only the tastes of the audience in Europe and America were considered, and the hobbies and interests of the domestic audience were not considered and deeply analyzed during the production period of this film.

After that the film and animation publication industry entered the stable development stage in our country, although the number of the film and animation publication works published is constantly increasing, most of the film and animation publication works are losing money. Of course, the Boonie Bears cartoons published by Shenzhen Huaqiang and the Pleasant Goat and Big Big Wolf cartoons are exceptions which had respectable income at the box office. Under the background of that the countries vigorously advocate and develop the movie and television culture industry in recent years, the film and animation publication industry has achieved some great successes in our country.

\section{THE NEW CHARACTERISTICS OF MARKET CHANGES OF THE FILM AND ANIMATION PUBLICATION}

To better embody the market value of the film and animation publication in our country, firstly, the market trend of development and the latest trend must be cleared. Then, the development policies and suggestions must be pertinently proposed according to the development trend. At present, the latest changes of the film and animation publication market are mainly embodied in the following three aspects:

\section{A. More Characteristics of Ancient Chinese Art Are Presented}

The film and animation publication has always adhering to the absorption of the traditional culture and Chinese characteristics elements from the initial stage of development to the rapid stage of development. It is really not easy to form the development situations today. During the period from the end of the 1950's to the middle of the 1960's, the absorption progress of Chinese traditional characteristic artistic languages, bright signs and esthetic sentiment began to be discussed in the film and animation publication industry in our country to gradually product the film and animation works with Chinese characteristics. For example, the cartoon The Monkey King adopted the 3D technology in which the well-known image of the Monkey King was shaped through the integration of ancient Chinese temple arts, drama, new year pictures and ancient painting and perfect details handling; The portrayal of the image of Sheng $\mathrm{Mu}$ in the cartoon The Magic Lotus Lantern not only show woman's softness, elegance and modesty but also show woman's flexility beauty and power beauty, and the inner beauty and the outer beauty of ancient Chinese women are integrated to form the essence of ancient traditional culture of China.

\section{B. More Development Characteristics of Current Era Are Presented}

In the 1990s, the development of the film and animation publication of China has comparative lag and delay compared with the level of the film and animation in the world. The film and animation publication is not very satisfactory just because of the lack of effective creation and reasonable planning, and the investment get not appropriate returns that seriously affect the cultivation and development of talents. The film and animation publication industry also has the advantages of congenital development because of its brilliant development period ever appeared. In the later stage of development, the further development of Chinese film and animation publication industry is promoted by vigorously developing 3D production technology and other characteristic elements of the times based on the absorption of Chinese culture connotation and ethnic flavor. Chinese film and animation publication is elevated to a new development height by the introduction of these technical elements.

\section{More Attention Is Paid to The Creative Practice of The Details}

Firstly, the application of the traditional elements in the production and publication of the film and animation emphasis the application of the traditional elements and the theme background in the publication of the film and animation. An attempt is made for the completion of the design of cartoon rendering effect to integrate 3D production technology. The integration of ethnic flavor elements and the worldwide popular 3D studio technology bring not only the visual impact but also the national affability. The publication design of the film and animation Mengdie not only bring fun and enlightenment to the audience but also raise the national affability of the audience; The film and animation A Girl on A Star shows the gap of the network world and the real world, and embodies the era sensation and the speed sensation by the later integration with the help of the $3 \mathrm{D}$ software used for design. Especially at the aspect of the portrayal of the facial expressions of the heroine, the facial features, headdress and dress show the east classic beauty because of the application of the modern animation technology. The film and animation work is very different from the film and animation works in America and Japan at the aspects of the overall shape and the color design.

\section{FAVORABLE FACTORS OF THE MARKET VALUE EMBODIMENT OF FILM AND ANIMATION PUBLICATION OF CHINA}

As is stated above, although the current market size of the film and animation publication of China is smaller, and its development also experienced many twists and turns, the 
film and animation publication industry has more market space because of the huge market demand under the background of that the country vigorously support the development of cultural industries. Especially, the film and animation publication of China has good development opportunities at several aspects at present:

\section{A. The Film And Animation Publication Industry Has Greater Market Space of Development in Our Country}

To better promote the development of the film and animation publication industry of China, it is explicitly proposed in Suggestions on Promoting The Development of Animation Industry of China introduced by the country that the country will promote the creation and publication ability of the film and animation industry to reach the development level of the big and strong countries of animation within the next five to ten years, and set a clear objective for the film and animation publication industry of China. After 2004, although the speed of development of the film and animation publication industry of China was low, the market size of the film and animation publication industry of China reached 5.5 billion Yuan in 2010. From this point of view, the film and animation publication industry has greater development space, and the film and animation publication industry of China will has more rapid development space and development speed in the coming years.

\section{B. The Film And Animation Publication Industry Has More And More Experience of Market Operation}

The film and animation publication has its own rules. Especially for a good film and animation work, if it can meet the psychological demands of cultural consumption of the customers when it is published, it must get the acceptance of the audience and the respectable income at the box office. During the process of the film and animation publication, the producers and the publishers can get the benefit and the operational experience of the film and animation publication through the broadcast of their works. Especially in the present film and animation works, some shortages in the previous film and animation works such as focusing on messaging, roughening and infantness are eliminated, and the prejudices of the audience to the traditional film and animation works are changed by the corresponding propaganda and guidance.

\section{The Brands of The Film And Animation Publication of China Has Been Initially Formed}

In 2011, the total time of the film and animation works of China published is 260,000 minutes, and the total number of the film and animation works of China published is 435 . In 2012, the total time of the film and animation works of China published is 220,000 minutes, and the total number of the film and animation works of China published is 295 . Although the total time of the film and animation works of 2012 is less than 2011, the market share is greatly improved. The market share of the film and animation works of China was only $19.18 \%$ in 2011 , but it increased to $34.32 \%$ in 2012 . Science 2004, the film and animation publication industry of China had faced a very important rapid development period.
China had emerged as the biggest country of the film and animation publication in the world in 2008, and its profound impacts in the world had been constantly expanded. Some film and animation works had initially formed their own influence and brands, and the initial international market forces of the film and animation of China had been initially formed.

\section{EXPANDING APPROACHES OF THE MARKET VALUE OF The FILM AND ANIMATION PUBLICATION OF CHINA}

Aiming at the current situation of the film and animation publication of China, it is very important to constantly expand the industrial value chain of the film and animation publication of China to better embody and expand the market value of the film and animation publication according to the development direction of the international film and animation publication.

\section{A. Increasing The Additional Value of The Film And Animation Publication Industry in Our Country}

Firstly, the cultivation mode of the film and animation publication talents should be improved. The film and animation publication industry of China will face the situation of rapid development in the coming period in which the corresponding talents must be required for its development. Especially, the cultivation of comprehensive talents of the film and animation publication must be enhanced; these talents should not only have the corresponding technologies capabilities but also have the international vision and creative thinking ability. In the specific talents cultivation process, the school should launch the courses about cultivation of creative thinking ability and add the practice session to guide the students to accumulate more historical and cultural knowledge and literacy. At the same time, in the process of talents cultivation, the talents cultivation should be in line with the international film and animation publication market to make the talents have the international vision and build the foundations for the development of the film and animation publication of China in the international market. The mode of talents cultivation should be in line with the market demand to cultivate a lot of professional talents with theoretical foundation and practical ability.

Secondly, the style of film and animation publication with Chinese characteristics should be formed. In the development process of the film and animation publication industry of China, we should constantly improve the production technology and the publication level of film and animation. In addition, we should pay more attention to the absorption of the national culture elements rather than blindly copy the styles of film and animation of Japan, Korea or Europe and America, and form the ethnic flavor and style of the film and animation works of China.

\section{B. Building The Chain of The Film And Animation Publication Industry}

In the publication processes of film and animation works, more attention should be paid to the creation and improvement of the marketing capability of film and 
animation publication of China, especially to the improvement through the marketing forms combination. In the earlier stage of film and animation work publication, the collection and arrangement of the relevant information can be carried out through the Internet and other ways to make investigation and analysis for the market demand and the consumers' demands. In the production process of film and animation work, the works such as marketing, propaganda and guidance can be performed. Especially, more attention must be paid to the integration of the traditional media and the new media and the integration of online work and offline work. In addition, some features and creative contents related to the film and animation work can be regularly produced and published to catch attention of the audience and improve the effect of market publicity. In the later stage of film and animation publication, its market value should be fully found by further press conference, releasing the trailer and producing some derivatives related to the film and animation work.

\section{Improving The Market Competitiveness of The Film And Animation Publication Industry in Our Country}

Firstly, the country should further strengthen the system reform of cultural industries to better adapt to the development of the film and animation publication industry. At present, the domestic film and animation publication market has certain monopoly behavior which caused the situation of that some themes and buying prices of film and animation works are suppressed. The country should strengthen the system reform of cultural industries, contribute to the changes in the oligopoly market structure of the film and animation publication and promote the formation of market competition system of the film and animation publication industry of China in order to provide better platforms for the broadcast of the film and animation works of China. At the aspect of approval of the film and animation works, ranking system method is suggested to better meet the different consumption demands of the different consumer groups in different age groups for the different film and animation works, and provide convenience for the integration of the film and animation works in the international market to enhance the international competitiveness of the film and animation publication industry of China.

Secondly, the development and supervision of the derivatives related to the film and animation works should be enhanced. The development of the derivatives related to the film and animation works is very important for the film and animation publication. The country should ensure the allaround development of the development, production and sales of the derivatives of the film and animation works by the guarantee of the relevant laws. At the same time, the country should enhance the supervision and ensure the intellectual property right in order to improve the quality of the derivatives of the film and animation works and enhance the degree of belief of consumers.

\section{REFERENCES}

[1] Lijun Sun. Analysis of Classical Film And Animation Works [M]. Beijing: Ocean Press, 2012.

[2] Huilin Zhang. History of The Chinese Animation Art of The 20th Century [M]. Xian:Shanxi People's Fine Arts Publishing House, 2012.

[3] Jiaguo Li. On Structure Optimization of The Chinese Animation Industry[M].Nanjing:Nanjing University Press, 2012.

[4] Group of The Animation Industry Annual Report. China Animation Industry Annual Report (2004-2005) [C]. Beijing: Ocean Press, 2006.

[5] Bin Lu, Yuming Zheng, Xingzhen Niu. Blue Book of AnimationAnnual Report on Development of China's Animation Industry (2011) [C]. Beijing: Soical Sciences Academic Press, 2011.

[6] Xiaoming Zhang. Annual Report on Development of China's Cultural Industries (2011) [C]. Beijing: Soical Sciences Academic Press, 2011. 